\title{
A relação professor-aluno em um curso de italiano para fins acadêmicos Annita Gullo Simone Flacschen
}

RESUMO: Apresentamos nesse artigo os resultados de uma pesquisa de base etnográfica sobre a relaçāo professor-aluno em um curso de italiano para fins acadèmicos; identificaçăo de alguns impactos desse tipo de relaçăo sobre o processo ensino-aprendizagem; identificaçāo de estrarégias pedagógicas utilizadas nesse contexto educacional.

PALAVRAS-CHAVE: ensino-aprendizagem; italiano língua estrangeira; italiano para fins acadêmicos; relaçăo professor-aluno.

Ormai da diversi anni uno degli aspetti che caratterizzano gli studi linguistici e glottodidattici ì l'interesse verso l'analisi e le modalità di insegnamento dei linguaggi specialistici. Paolo Balboni (in: Troncarelli; Vannini, 1995)

O desenvolvimento da abordagem LSP - Languages for Specific Purposes / línguas para fins específicos - para o ensino/aprendizagem de línguas estrangeiras, viabilizado sobretudo por pesquisas em Lingüística Aplicada, além de proporcionar uma ampliação dos horizontes no campo da didática dessas línguas, trouxe novos olhares sobre aspectos educacionais freqüentemente investigados em outros contextos; um desses aspectos é a relação professor-aluno.

A abordagem em questão é de origem anglo-americana e começou a ser desenvolvida na década de 60 do século XX. Ela tornou possível uma formação em língua estrangeira de nível técnico, voltada para fins acadêmicos e profissionais. Neste sentido, os cursos norteados por essa abordagem têm, como objeto de estudo na língua estrangeira, a área acadêmica ou profissional dos alunos. Quando os fins 
são acadêmicos, a abordagem é identificada como LAP - Languages for Academic Purposes; quando os fins são profissionais, é identificada como LPP - Languages for Professional Purposes - ou LOP - Languages for Ocupacional Purposes.

Em cursos de línguas estrangeiras que focalizam a língua coridiana, comum a todos, podemos encontrar, por exemplo, alunos que pertençam a áreas profissionais ou acadêmicas diferentes. Esse é um aspecto geralmente irrelevante para o desenvolvimento desses cursos, porque a matéria a ser ensinada/aprendida é a língua coridiana na língua estrangeira. Já os cursos de línguas para fins específicos, que seguem a abordagem LSP, são baseados na análise das necessidades dos alunos que pertencem a uma única área acadêmica ou profissional, ou pelo menos a áreas afins; eles estudam a língua estrangeira de nível técnico, da área deles.

Segundo Paolo Balboni (in: Troncarelli; Vannini, 1995), a grande demanda, em diversos países do mundo, por cursos dessa natureza - gerada por fatores sobretudo sócio-econômicos - intensificou as pesquisas lingüísticas e glotodidáticas na área. Atualmente no mercado editorial, além dos tradicionais manuais didáticos para o ensino/aprendizagem das línguas estrangeiras, há também à disposição diversos manuais didáticos voltados para cursos LSP, de áreas especializadas, tais como a Medicina, a Arquitetura, o Direito, a Economia, a Administração.

A atenção, por parte dos glotodidatas italianos, dedicada à abordagem LSP, de origem anglo-americana, $\mathrm{e}$ às questōes ligadas à mesma, gerou recentemente uma espécie de boom editorial na Itália. Várias editoras italianas de prestígio publicaram manuais didáticos voltados para o ensino/aprendizagem do que Paolo Balboni (2000) chama de "microlínguas científico-profissionais", que são as variaçōes da língua, objetos de estudo nos cursos LSP.

Segundo Giovanni Freddi (in: Balboni, 2000), o ensino/aprendizagem das línguas para fins específicos implica significativas mudanças no modelo canônico aplicado para a língua comum. Uma dessa mudanças diz respeito à relação professor-aluno. Com o termo "relação", queremos nos referir aqui ao relacionamento, à ligação entre estes dois sujeitos, considerando o poder em sala de aula e o conhecimento que esses sujeitos têm dos conteúdos envolvidos no processo ensino/aprendizagem. 
É preciso estar claro que "relaçáo" não é o mesmo que "interação" Este último termo significa a ação que se exerce mutuamente entre duas ou mais pessoas (Ferreira, 1986). Podemos interagir com várias pessoas por meio da conversação e ter, com cada uma delas, uma relação diferente. $O$ tipo de interação que se estabelece entre os indivíduos depende de vários fatores, entre os quais citamos a idade, a condição econômica e a relaçáa social. Assim, por exemplo, costumamos conversar de um modo com uma pessoa idosa e de outro com uma criança; de um modo com o nosso chefe, e de outro com um amigo íntimo.

As situaçóes que envolvem interação por meio de diálogos podem ser analisadas por meio do parâmetro distância social versus poder do indivíduo. Dizemos que uma relação é simétrica quando não há distância social e o poder é equilibrado. É o caso, por exemplo, da interação entre dois diretores de empresas. A relação é assimérrica quando há distância social e desequilíbrio de poder, como ocorre, por exemplo, na interação entre chefe e empregado.

A relaçāo entre poder e conhecimento pode contribuir para a simetria ou a assimetria nas relaçōes sociais. Sobre esse aspecto, recorremos à teoria foucaultiana (Machado, 1995):

Saber e poder se implicam mutuamente: nāo há relaçāo de poder sem constituição de um campo de saber, como também, reciprocamente, todo saber constitui novas relaçōes de poder. Todo ponto de exercício do poder é ao mesmo tempo um lugar de formação de saber.

No campo educacional, a relação professor-aluno é tipicamente assimétrica: o professor controla o discurso e, portanto, detém o poder (Moita Lopes, 2002). Ele é, segundo Vigotsky (in: Rego, 1995), o par mais competente, o elemento que possibilita a construção do conhecimento. $O$ aluno é um elemento que não tem o conhecimento e, por isso, não detém o poder. Moita Lopes (2002) afirma o seguinte sobre a questáo da relação assimétrica entre professor e aluno:

Na sala de aula [...] o desenvolvimento de conhecimento comum não é uma atividade simples para alunos e professores. A dificuldade está, principalmente, calcada na relação assimétrica entre o aluno e 
o professor, que atua como empecilho para o que Bruner chama de handover, ou seja, o ponto em que o adulto, isto é, o professor, passa a competência para o aluno. $O$ ato de passar a competência para o aluno implica, portanto, que o professor é o possuidor de um conhecimento que o aluno não tem, e isto os envolve em uma relação de poder, que é extremamente importante para a compreensāo de como o conhecimento comum é criado na sala de aula através da interação entre aluno e professor.

Alice Maria da Fonseca Freire (Cox; Assis-Peterson, 2003) reforça essa idéia com a seguinte afirmação:

[...] o discurso da sala de aula é caracterizado pela seqüência Iniciaçäo, Resposta, Avalią̧ão, cabendo ao professor o primeiro e o terceiro movimentos, e ao aluno, apenas o segundo. Uma análise rápida da afirmação acima demonstra que a distribuiçāo do poder não é equilibrada nessa interaçāo: o professor não só tem direico a mais turnos, como também a ele cabe iniciar a sequêencia e avaliá-la. Aos alunos cabe apenas responder. Portanto, não se trata apenas de uma questão quantitativa, mas também qualitativa: a questão não se esgota em uma análise de quem fez mais uso da palavra, mas para que a palavra é usada. Essa análise se aplica praticamente a todas as salas de aula, mas, no caso da sala de aula de língua estrangeira, há um fator complicador, uma vez que o aluno é chamado a participar da interação usando um código que ele está aprendendo, a própria língua estrangeira. Esse fato tende a reforçar a centralização do poder na mão de uma pessoa - o professor.

O arranjo espacial em sala de aula é um outro fator que determina o tipo de interação estabelecida entre os indivíduos envolvidos no processo educacional. $\mathrm{O}$ arranjo tradicional de sala de aula tem contribuído para a relação assimétrica entre os sujeitos: o professor ocupa uma posição de destaque na parte dianteira da sala de aula, e os alunos ocupam carteiras enfileiradas, de frente para o professor. Esse arranjo dificulta o igual acesso dos participantes à interação.

$\mathrm{Na}$ didática das línguas para fins específicos, porém, a relação professor-aluno deverá apresentar-se diferente, principalmente porque, apesar de o professor possuir o domínio da língua-alvo comum e o domínio didático, ele nāo domina - salvo raras exceçōes - a área especializada do aluno, que é justamente o objeto de estudo na língua estrangeira.

De acordo com Paolo Balboni (2000), "o modelo 'o-professor-ensina-coisasque-sabe-a-um-aluno-que-não-sabe' se adapta à cotidianidade da turma da escola 
auto-referencial, mas não pode ser aplicado ao ensino das microlínguas científicoprofissionais" Balboni apresenta as seguintes razōes para esse fato:

1) "o ensino microlingüístico é por natureza hetero-referencial" isto é, o seu planejamento e realização dependem do mundo externo, do lugar onde a microlíngua é utilizada;

2) o professor nāo conhece a microlíngua com profundidade e segurança, porque ele não pertence à área científico-profissional do aluno;

3) "o ensino da microlíngua é dirigido a um estudante especialista"; ele geralmente não domina as variaçōes cotidianas da língua estrangeira, mas domina o conteúdo tratado na microlíngua.

Destacamos que estes fatores impedem que, nos cursos LSP, o método tradicional seja adotado. Este paradigma se baseia no modelo "o-professor-ensina-coisas-quesabe-a-um-aluno-que-nāo-sabe"

Um outro fato importante que contribui para descaracterizar a típica assimetria da relação professor-aluno é que os cursos de línguas para fins específicos geralmente são direcionados a alunos que já tenham concluído pelo menos um curso básico da língua estrangeira. São, portanto, alunos que já têm um certo domínio da língua comum.

A reflexāo sobre os princípios que sucintamente apresentamos, aplicados à didática da língua italiana para estrangeiros, levou à realização de uma Pesquisa de Mestrado na Faculdade de Letras da UFRJ, intitulada $A$ relą̧ão professor-aluno em um curso de italiano para fins acadêmicos. A investigaçāo objetivou descrever e analisar essa relação no contexto citado, e identificar alguns impactos que ela provocaria no processo ensino/aprendizagem. Trataremos aqui de apontar alguns dos resultados dessa investigação.

Optamos pela etnografia como metodologia de pesquisa. $\mathrm{O}$ trabalho de campo foi feito em um curso intitulado L'arte del costruire: curso de italiano técnico, criado especialmente para o desenvolvimento da pesquisa, e oferecido como curso de 
extensão pelo Setor Cultural da Faculdade de Letras da mesma Universidade no segundo semestre de 2004. O curso foi dirigido a alunos de Arquitetura, Engenharia Civil e Belas Artes, entendidas como áreas afins, mas participaram também alunos da Faculdade de Letras. A coleta de dados foi realizada através dos seguintes instrumentos: diário da professora-pesquisadora; diário de duas informantes; gravaçōes em áudio e em vídeo da maioria das aulas; e questionários.

O curso realizou-se nos meses de setembro e outubro de 2004. Foram 15 encontros de uma hora e meia cada, sendo dois encontros por semana. A carga horária total foi de 22 horas e meia. Freqüentaram e concluíram o curso 11 alunos. Este grupo discente era formado por estudantes das faculdades de Arquitetura e Urbanismo, Letras, Engenharia Civil e da Escola de Belas Artes.

O principal material didático utilizado foi uma apostila que desenvolvemos com base no manual didático L'arte del costruire (Troncarelli; Vannini, 1995), projetado para o ensino/aprendizagem do italiano da Arquitetura.

Os objetivos do curso de extensão foram os seguintes: compreensão de textos em italiano ligados à Arquitetura, Engenharia Civil e Belas Artes; identificação das estruturas sintáticas italianas recorrentes em textos ligados às referidas áreas acadêmicas; conhecimento e utilização de léxico ligado às referidas áreas; aperfeiçoamento da capacidade de produção oral e escrita na língua italiana, no contexto das referidas áreas; e reflexão crítica sobre o modo de conceber o conhecimento científico das referidas áreas nas culturas brasileira e italiana.

A análise dos dados coletados durante a realização do curso de extensão partiu da existência de dois grupos diferenciados de alunos na sala de aula:

GRUPO 1: alunos dos cursos de Arquitetura, Belas Artes e Engenharia Civil GRUPO 2: alunos do curso de Letras ou extra-universitários

A relação entre a professora e esses dois grupos de alunos mostrou-se diferente. De qualquer forma, a situação da professora era a seguinte: possuía o domínio didático e domínio do italiano, língua comum, mas não possuía domínio das áreas 
especializadas do grupo 1 de alunos - Arquitetura, Engenharia Civil e Belas Artes; o conteúdo referente a essa áreas era, no caso, o objeto de estudo no curso.

Em relação aos alunos, verificamos duas situaçōes. O grupo 1 apresentava domínio das áreas especializadas. Durante as aulas, muitas vezes a professora "dependia" do conhecimento específico desse grupo. Por isso, a relação entre a professora e os alunos desse grupo se caracterizou por um equilíbrio do poder em sala de aula, apesar de haver uma distância social. Sob esse aspecto, a relaçāo foi mais simétrica do que em cursos de língua comum.

Quando as etapas de iniciação, resposta e avaliaçãa - tradicionalmente seguidas em cursos de língua comum - foram aplicadas nas aulas do curso de extensāo, verificamos que a iniciação e a resposta foram como nas aulas tradicionais, mas a avaliaçāo foi diferente, porque a professora, no que diz respeito às áreas especializadas, não era capaz de avaliar. Essa etapa, muitas vezes, era realizada pelos alunos do grupo 1.

Já o grupo 2 não tinha nenhum conhecimento inerente às áreas especializadas. A relação entre a professora e esse grupo de alunos - sob o aspecto do poder em sala de aula - seguiu a tendência tradicional, ou seja, foi assimétrica; caracterizou-se pelo desequilíbrio de poder e pela distância social. A professora apresentava um conhecimento mínimo das áreas especializadas, obtido sobretudo através da pesquisa e do estudo que realizou para planejar o curso e cada aula. Esse conhecimento, apesar de mínimo, representou uma vantagem da professora em relaçāo ao grupo 2 , e isso possibilitou a detenção do poder por parte da professora.

No curso de extensão, observamos que tanto a professora quanto os alunos do grupo 1 exerceram a função de facilitadores da aprendizagem, uma vez que, na construção do conhecimento comum, esses participantes do processo contribuíram com as suas respectivas competências.

Devido a isso, pudemos observar que no curso de extensão foi posta em prática um tipo de didática que Balboni (2000) denomina didática colaborativa ou cooperativa. Sobre esse paradigma, o autor afirma o seguinte: 
No ensino microlingǘstico, o ato didático vê os dois sujeitos - estudante e docente - em posição de igual dignidade, de igual responsabilidade, com deveres e competências complementares: o termo "microlíngua" é dividido nos seus dois componentes, e o estudante traz a sua competência relativa ao "micro", ao signifié, enquanto o professor contribui seja com o signifiant, com a própria competência na "língua", seja sobretudo com o seu domínio das técnicas de análise lingüística e o seu conhecimento dos processos de aprendizagem.

No curso de extensão, a professora utilizou determinadas estratégias para exercer a sua função de facilitadora no processo de construção do conhecimento em sala de aula. Algumas dessas estratégias foram as seguintes:

1) Apoio no domínio da língua comum. A professora, no decorrer do curso, procurava por meio do seu domínio da língua comum superar a falta de domínio nas áreas especializadas dos alunos.

2) Apoio na distância social. Apesar de termos verificado a ocorrência de uma maior simetria, no que tange ao poder em sala de aula, entre a professora e os alunos do grupo 1, a professora manteve a autoridade que a hierarquia institucional lhe confere. Era ela quem tomava todas as decisōes, por exemplo, sobre o direcionamento das aulas.

3) Apoio no domínio didático. Esse aspecto pôde ser percebido em determinadas situaçōes ocorridas em sala de aula. Um exemplo disso é que, quando tanto a professora quanto os alunos do grupo 1 não entendiam algum termo técnico ou apresentavam dúvida sobre a utilizaçāo de um termo técnico, geralmente a professora resolvia a situação pedindo-lhes que pesquisassem o assunto e apresentassem na aula seguinte. Assim, superava esse tipo de obstáculo e avançava com o material didático.

A relação professor-aluno estabelecida no curso de extensāo L'arte del costruire: curso de italiano técnico provocou impactos positivos no processo ensino/aprendizagem. A didática colaborativa que se desenvolveu no curso levou, conforme afirmamos anteriormente, a um equilíbrio do poder em sala de aula. Tendo em vista que os alunos do grupo 1 sabiam que eram eles - e nāo a professora - os 
especialistas nas áreas, isso proporcionou uma maior segurança aos alunos e serviu para aumentar a motivação e a participação deles no processo de construção do conhecimento comum.

Esses foram alguns dos resultados obtidos pela pesquisa. Por fim, queremos chamar a atenção para algumas particularidades da abordagem LSP, que a tornam ímpar no cenário pedagógico.

O ensino/aprendizagem de línguas para fins específicos atende perfeitamente ao modelo educacional valorizado por muitos estudiosos que se inspiram nas teorias vygotskiana e bakhtiniana do conhecimento e significado, respectivamente. Eles caracterizam a educação como um processo comunicativo em que conhecimentos e significados são construídos mediante a atuação conjunta entre professores e alunos. Há uma valorizaçáo de abordagens educacionais que propiciem o desenvolvimento de conhecimentos compartilhados. A LSP é uma dessas abordagens: abre espaço para as experiências e os interesses dos alunos, fazendo com que os conteúdos curriculares sejam mais significativos para eles.

Esse tipo de abordagem representa também uma espécie de desafio tanto para professores quanto para alunos. Ambos vêm de uma tradição de aulas expositivas, acostumados com a relaçāo assimétrica entre eles. Nos cursos LSP é preciso que ambos tenham coragem para assumir novos papéis. O professor precisa aceitar a sua necessidade de compartilhar com os alunos o poder em sala de aula. Precisa encarar com naturalidade o fato de ter de abrir espaço para o conhecimento técnico dos alunos no desenvolvimento das aulas. Precisa aceitar que ele não é o único possuidor do conhecimento significativo.

Por sua vez os alunos precisam deixar de lado a sua posição tradicionalmente passiva na sala de aula - de somente receber o conhecimento do professor -, e desenvolver uma disposiçāo para participar ativamente das aulas de forma constante, contribuindo mediante o compartilhamento do seu conhecimento técnico. É preciso que o aluno conheça e entenda o tipo de didática educacional em que está envolvido para aceitar a função do professor, cumprir a sua própria função e aproveitar ao máximo o curso, que é totalmente voltado para as suas necessidades. 
Enfim, a abordagem LSP é um convite para que se destruam preconceitos ligados sobretudo à relação professor-aluno e às funçōes que esses dois sujeitos devem assumir no processo educacional, e para que o ensino/aprendizagem de línguas não se resuma à tríade língua comum-literatura-cultura.

ABSTRACT: In questo articolo presentiamo i risultati di una ricerca di base etnografica sul rapporto professore-allievo in un corso di italiano con obiettivi accademici; identificazione di alcuni effetti di questo rapporto sul processo di istruzionelapprendimento; identificazione di strategie pedagogiche utilizzate in questo contesto educativo.

PALAVRAS-CHAVE: istruzionelapprendimento; italiano lingua straniera/italiano con obietrivi accademici; relazione professore-allievo.

\section{Referências Bibliográficas}

BALBONI, Paolo. (2002). Didattica dell'italiano a stranieri. Roma: Bonacci. (2000). Le microlingue scientifico-professionali: natura e insegnamento. Torino: UTET.

BLOOR, M.; BLOOR, T. (1986). Languages for Specific Purposes: practice and theory. CLCS Occasional Paper, no 19, Autumn.

CILIBERTI, Anna. (1981). Linsegnamento linguistico per scopi speciali. Bologna: Zanichelli.

COX, Maria Inês Pagliarini; ASSIS-PETERSON, Ana Antônia (2003). Cenas de sala de aula. Campinas: Mercado de Letras.

EDWARDS, D.; MERCER, N. (1987). Common knowledge. Londres: Routledge.

FERREIRA, Aurélio Buarque de Holanda (1986). Novo dicionário Aurelio da Lingua Portuguesa. Rio de Janeiro: Nova Fronteira.

HUTCHINSON, Tom; WATERS, Alan (1987). English for Specific Purposes: A learning-centred approach. Cambridge University Press.

MACHADO, R. (1995). "Introdução." In: FOUCAULT, M. Microfisica do poder. Rio de Janeiro: Graal.

MOITA LOPES, Luiz Paulo (2002). Oficina de Lingüistica Aplicada: a natureza social e educacional dos processos de ensino/aprendizagem de línguas. Coleção Letramento, Educação e Sociedade. Campinas: Mercado de Letras.

Pesquisa interpretativista em Lingüistica Aplicada: a linguagem como condição e solução. Revista D.E.L.T.A., vol. 10, n² 2, 1994. 
RIBEIRO, Luiz Freire. A relạ̧ão de poder na sala de aula: em busca de positividades. Dissertação de Mestrado. Natal - RN, 2001.

SIGNORINI, I.; CAVALCANTI, M. C. (organizadoras) (1998). Lingǘstica Aplicada e transdisciplinaridade questōes e perspectivas. Campinas: Mercado de Letras.

TRONCARELLI, D.; VANNINI, E. (a cura di). (1995). Larte del costruire. Guida per l'insegnante.

Roma: Bonacci.

VYGOTSKY, L. S. (1998). Linguagem, desenvolvimento, aprendizagem. São Paulo: Scipione. (1984). A formaçāo social da mente. São Paulo: Martins Fontes. 